\title{
PERENCANAAN STRATEGIS SI/TI PADA DOCUMENT MANAGEMENT MENGGUNAKAN WARD AND PEPPARD (STUDI KASUS : PT. VISIONET DATA INTERNATIONAL)
}

\author{
Agustinus Fritz Wijaya', Vincentius Dhendy Randya Damara² \\ Program Sarjana Sistem Informasi \\ Universitas Kristen Satya Wacana \\ email : agustinus.wijaya@uksw.edu,682016016@student.uksw.edu
}

J1. Diponegoro 52-60 Salatiga - Indonesia 50711

\begin{abstract}
PT. Visionet Data International is a company engaged in the field of IT that serves Total IT Managed services. Because the development of Information Systems and Information Technology (IS / IT) in fulfilling the company's vision and mission, a good plan is needed. In this research focuses on the documentation management system in which there is no good company documentation management in accordance with the provisions in force. Regarding data collection methods, this research uses interviews with company's employees. This research is a qualitative descriptive study using the Ward and Peppard method. Which includes SWOT analysis, Value Chain analysis, PEST analysis, application mapping analysis using McFarlan Strategic Grid and analysis of Proposed Information Systems. This research results in the form of application portfolio recommendations such as the development of Document Management in the form of Web-based applications in which all processes are integrated into one. So in the process of submitting new documents to the process of issuing documents can be done in an application which can support the reduction in the use of paper in the company.
\end{abstract}

Kata kunci: Documentation management, Ward and Peppard, Value Chain, SWOT,

Application portfolio

\section{Abstrak}

PT. Visionet Data International merupakan perusahaan yang bergerak pada bidang IT yang melayani jasa Total IT Managed services. Karena pengembangan Sistem Informasi dan Teknologi Informasi (SI/TI) dalam pemenuhan visi dan misi pada perusahaan maka dibutuhkan sebuah perencanaan yang baik. Dalam penelitian ini berfokus pada sistem pengelolaan dokumentasi yang dimana belum adanya manajemen dokumentasi perusahaan yang baik sesuai dengan ketentuan yang sedang berlaku. Mengenai metode pengumpulan data, penelitian ini menggunakan metode wawancara dengan karyawan perusahaan. Penelitian ini merupakan penelitian deskriptif kualitatif dengan metode Ward and Peppard. Dimana meliputi analisis SWOT, analisis Value Chain, analisis PEST, analisis pemetakan aplikasi dengan menggunakan McFarlan Strategic Grid dan analisis Usulan Sistem Informasi. Penelitian ini menghasilkan bentuk rekomendasi portofolio aplikasi seperti pengembangan Document Management ke dalam bentuk aplikasi yang berbasis Web yang semua proses didalamnya terintegrasi menjadi satu. Sehingga dalam proses pengajuan dokumen baru hingga proses penerbitan dokumen dapat dilakukan didalam aplikasi yang mana dapat menunjang pengurangan penggunaan kertas pada perusahaan.

Kata kunci:Manajemen Dokumen, Ward and Peppard, Value Chain, SWOT, Application portfolio 


\section{PENDAHULUAN}

Pengembangan Sistem Informasi dan Teknologi Informasi (SI/TI) membutuhkan perencanaan yang baik. Pengembangan SI/TI yang tidak struktur maupun tidak tertata, memenuhi kebutuhan perusahaan atau organisasi yg bersifat sementara, tidak ada skala prioritas maupun tidak berjalan dengan proses bisnis yang ada maka pada perusahaan perlu melakukan Perencanaan Strategis Sistem Informasi untuk mendukung proses bisnis utamanya. Strategis dalam arti bagaimana aksi-aksi yang akan dilakukan dalam jangka waktu yang panjang dan sifatnya sangat penting. Manfaat adanya Perencanaan Strategis Sistem Informasi agar menjadi lebih terarah dengan menggunakan berbagai metode Perencanaan Strategis Sistem Informasi. Maka dari itu Perenanaan Strategis Sistem Informasi diperlukan oleh seluruh organisasi.

PT. Visionet Data Internasional merupakan anak perusahaan PT Multipolar Tbk yang didirikan pada tahun 2006. Pada awalnya dengan nama perusahaan PT. Visionet Internasional berganti nama menjadi PT. Visionet Data Internasional pada awal tahun 2016. Sebagai perusahaan yang bergerak pada bidang IT yang melayani jasa Total IT Managed services. Layanan terkelola IT dari VisioNet adalah membantu dan mendukung client dalam mengelola operasi IT dan memastikan kinerja optimal serta keandalan dan efektivitas yang bertujuan agar dapat berfokus pada bisnis mereka. Bersertifikasi ISO 9001: 2008 dan PCI DSS. Dalam menunjang bisnisnya, PT. Visionet Data Internasional menggunakan sarana SI/TI. Salah satu contohnya aplikasi Document Management.[1]

Document Management merupakan aplikasi yang dikembangkan oleh PT. Visionet Data Internasional yang bertujuan mengelola dokumen-dokumen perusahaan seperti Policy, WI (Work Instruction), dan Procedure. Document Management terintergrasi dengan aplikasi V-Portal yang berfungsi sebagai tempat menyimpan semua jenis dokumen (Procedure, Policy, dan Work Instruction) beserta I-Top yang terintegrasi langsung dengan aplikasi Viona yang berfungsi untuk pengajuan dokumen dan proses revisi dokumen. Permasalahan saat ini adalah belum adanya manajemen dokumen perusahaan yang baik. Sehingga saat direview masih banyak dokumen yang kurang up-to-date dan karena PT. Visionet Data Management menerapkan ISO/EIC 20000 semua proses perubahan harus melewati proses change-management namun kenyataannya masih belum. Maka dari situ semua manajemen dokumentasi dalam perusahaan harus diotomatisasikan.

Penggunaan metode Ward and Peppard pada perusahaan PT. Visionet Data International lebih cocok dalam perencanaan strategis sistem informasi karena metode ini memiliki kerangka kerja yang jelas serta memiliki teknik analisis yang berfokus pada kebutuhan bisnis bukan berfokus pada teknologi seperti mencangkup analisis SWOT, analisis Five Forces Competitive, analisis Value Chain, metode Critical Succes Factors, metode Balanced Scorecard, dan McFarlan's Strategic Grid. Metodologi ini terdiri dari tahapan masukan dan tahapan keluaran (Ward \& Peppard, 2002). Untuk tahapan masukannya seperti analisis lingkungan bisnis internal, analisis lingkungan bisnis eksternal, analisis lingkungan SI/TI internal, dan analisis lingkungan SI/TI eksternal. Sedangkan tahapan keluaran seperti analisis strategi SI bisnis, analisis strategi TI, dan analisis strategi manajemen SI/TI.[2]

Perencanaan Strategis SI/TI dengan Pendekatan Ward and Peppard Model terdapat 2 tahapan yaitu tahapan input (masukan) dan output (keluaran). Tahapan masukan yaitu analisis bisnis internal, analisis lingkungan bisnis eksternal, analisis lingkungan SI/TI internal dan analisis lingkungan SI/TI eksternal. Sedangkan untuk tahapan keluaran yaitu strategi SI bisnis, strategi SI/TI dan strategi manajemen SI/TI. Ada beberapa metode pengolahan data yang digunakan yaitu Value Chain Analysis, SWOT Analysis, PEST Analysis, Five Forces Model Analysis, dan Strategic Grid McFarlan Analysis.[3]

Berdasarkan penelitian Perencanaan Strategis SI/TI dengan menggunakan metode Ward and Peppard yang dilakukan sebelumnya oleh Inge Gunawan Susanto pada tahun 2018 bahwa menghasilkan sebuah rekomendasi berupa portofolio aplikasi yang dapat dikembangkan dan diimplementasikan oleh PT. XYZ di masa mendatang.[1] 
Pada penelitian yang dilakukan oleh Jefree Fahana pada tahun 2018 yang meneliti tentang "Perencanaan Strategis Sistem Informasi untuk Pengelolaan Guru Sekolah Muhammadiyah" dengan hasil penelitian berupa bentuk rekomendasi portofolio kebutuhan SI/TI untuk pengelolaan guru sekolah dimasa yang akan datang berdasarkan matrik portofolio McFarlan.[4]

Kemudian pada penelitian yang dilakukan oleh Kuncoro Tri Setiadi dan Andeka Rocky Tanaamah pada tahun 2019 di Yayasan Lembaga Pelayanan Hukum Salatiga (YLPHS) masih seputar penelitian menggunakan metode Ward and Peppard yang dimana penelitian yang dilakukan menghasilkan portofolio Sistem Informasi memuat usulan-usulan aplikasi. Usulanusulan tersebut berguna untuk membangun SI/TI di YLPHS sehingga dapat meningkatkan kinerja dalam organisasi yang lebih efektif dan efisien.[5]

Dari ketiga penelitian tersebut adanya keselarasan dengan teori penelitiannya sehingga diharapkan dapat membantu meningkatkan kinerja bisnis di PT. Visionet Data Internasional yang mana akan memberikan nilai tambah berupa competitive advantage dalam persaingan bisnis. Penerapan sistem informasi akan bermanfaat jika penerapannya sesuai dengan visi dan misi serta tujuan perusahaan.[6]

Dengan demikian diharapkan adanya metode Ward and Peppard dalam Perencanaan Strategis SI/TI pada perusahaan PT. Visionet Data Internasional dapat memperbaiki proses manajemen dokumen perusahaan dengan melakukan berbagai proses yang mengelola informasi. Serta dapat meningkatkan kinerja bisnis pada PT. Visionet Data Internasional yang mana diiringi meningkatnya keunggulan kompetitif organisasi dengan merubah gaya dan cara berbisnis.

\section{METODOLOGI PENELITAN}

Metodologi merupakan kumpulan tata cara tertentu yang digunakan untuk meminimalkan resiko kegagalan, memastikan semua pihak yang berkepentingan serta meminimlkan ketergantungan individu, dan lebih menekankan kepada proses dan sasaran yang dintentukan. Beberapa metode yang digunakan dalam Perencanaan Strategis SI/TI meliputi analisis SWOT, analisis Value Chain, analisis PEST , analisa pemetakan aplikasi dengan menggunakan McFarlan Strategic Grid dan analisis Usulan Sistem Informasi. Dengan penelitian menggunakan deskriptif kualitatif dan responden Ibu Helen selaku Product Owner di Document Management dan Pak Ferry sebagai Compliance Officer di Document Management. Sehingga dalam pengambilan data dan fakta penulis melakukan berupa wawancara dengan responden dan melakukan pengamatan secara langsung di PT. Visionet Data International.[2]

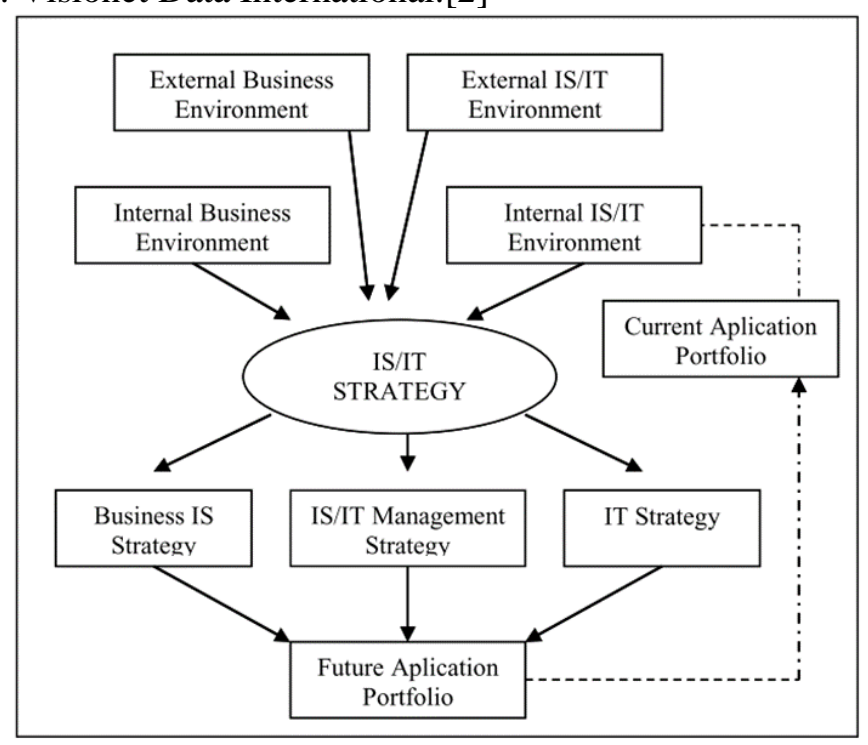

Gambar 1. Model Perencanaan Strategis SI/TI [Ward \& Peppard 2002] 
Dalam model versi ini terdiri dari tahapan masukan dan tahapan keluaran. Tahapan masukannya sendiri terdiri dari :

1. Analisis Lingkungan Bisnis Internal. Mengidentifikasi sejauh mana yang dilakukan oleh PT. Visionet Data Internasional untuk mencapai tujuan organisasi serta hal-hal apa saja yang perlu diperbaiki ataupun dikembangkan sehingga dapat meningkatkan keuntungan kompetitif perusahaan.[2]

2. Analisis Lingungan Bisnis Eksternal. Mengidentifikasi segala sesuatu yang terjadi diluar perusahaan. Adapun metode yang digunakan dalam analisa ini adalah metode PEST (Politik, Ekonomi, Sosial, dan Teknologi). [7]

3. Analisa Lingkungan SI/TI Internal. Perlu dilakukan assessment terhadap infrastruktur SI/TI yang digunakan oleh PT. Visionet Data Internasional sehingga dalam penggambilan suatu keputusan untuk membuat suatu strategi lebih lanjut.[7]

4. Analisa Lingkungan SI/TI Eksternal. Yang mencangkup trend teknologi dan pemanfaatannya, serta penggunaan SI/TI oleh kompetitor, pelanggan dan pemasok.[2]

Kemudian untuk tahapan keluaran terdiri dari Strategi SI bisnis, Strategi TI, dan Strategi Manajemen SI/TI, Dimana dalam penggunaan metodenya disini mencangkup analisis SWOT, analisis Value Chain, dan analisis pemetakan aplikasi dengan menggunakan McFarlan Strategic Grid [1]. Tahapan keluaran merupakan bagian yang menghasilkan suatu bentuk perencanaan strategis SI/TI yang isinya berupa :

1. Strategi SI bisnis, mencangkup bagaimana setiap unit bisnis akan memanfaatkan SI/TI. Seperti PT. Visionet Data Internasional yang memanfaatkan Document Management sehingga dapat mencapai sasaran bisnisnya dan meningkatkan efisiensi dan efektivitas perusahaan sehingga dapat disusun rekomendasi usulan Sistem Informasi yang dibutuhkan oleh perusahaan berdasarkan kebutuhan bisnis.[7]

2. Strategi TI, yang mencakup kebijakan dan strategi bagi pengelolaan teknologi dan sumber daya manusia SI/TI.[2]

3. Strategi Manajemen SI/TI, yang mencangkup mengenai aturan-aturan strategi yang ditetapkan dalam PT. Visionet Data Internasional untuk memastikan penerapan kebijakan SI/TI yang dibutuhkan, serta batasan-batasan dari aplikasi yang digunakan sudah sampai pada titik mana.[1]

Maka dengan itu semua akan menghasilkan pemetakan aplikasi dengan menggunakan McFarlan Strategic Grid di PT. Visionet Data Internasional. Dimana dalam penyusunannya berdasarkan kategori High Potential, Strategic, Support, dan Key Operation. Hasil dari tahapan ini adalah sebuah portofolio kandidat aplikasi yang sedang akan direncanakan pada masa depan perusahaan serta untuk mengintegritaskan setiap unit dari perusahaan dan menyesuaikan perkembangan teknologi dengan perkembangan perusahaan.[1]

\section{HASIL DAN PEMBAHASAN 3.1 Visi dan Misi Perusahaan}

Visi PT. Visionet Data International :

Menjadi perusahaan idaman dan partner kerja yang terpercaya di dalam industri yang kami pilih.[8]

Misi PT. Visionet Data International :

Menyediakan end-to-end layanan terkelola IT yang mempercepat klien kami dalam meraih tujuan bisnisnya.[8] 


\subsection{Analisis Lingkungan Bisnis Internal dan Eksternal \\ 3.2.1 Analisis SWOT}

Analisis SWOT terbagi menjadi empat komponen dasar, yaitu: strength (kekuatan), weakness (kelemahan), opportunity (peluang), serta threat (ancaman)[1]. Dari keempat komponen dasar tersebut dianalisa menurut hasil pengumpulan data melalui metode berupa wawancara pada aplikasi Document Management di PT. Visionet Data International. Sehingga diperoleh analisis SWOT sebagai berikut : Kekuatannya adalah Document Management saat ini sudah terstruktur dengan baik sehingga menjadi media sebagai pemberi arahan disuatu pekerjaan bagi pegawaipegawai di PT. Visionet Data International seperti dokumen Work Instruction, Procedure, dan Policy, dari segi SDM sudah mumpuni dalam menggunakan Document Management karena sebagian besar pegawai dasar keahliannya sudah paham mengenai TI dan paham dengan teknologi yang semakin berkembang. Kemudian dari Kelemahannya tersendiri adalah proses pembuatan dokumen (Procedure, Policy, dan Work Intruction) masih dilakukan secara manual. Dimana pembuatan dokumen masih ada yang dilakukan diluar sistem. Untuk proses pemeriksaan, persetujuan, dan penandatanagan masih dilakukan dengan menggunakan tanda tangan tinta basah. Sehingga untuk dokumen yang telah disetujui telah dipublikasi di aplikasi Vportal serta dalam proses pencarian Dokumen pengguna harus datang ke Compliance Officer untuk menanyakan letak beserta judul nama Dokumennya sehingga dapat menyebabkan ketidakefektifan dalam pekerjaan. Peluangnya ialah dapat meminimalisir penggunaan kertas (hardcopy), pada proses pencarian dokumen bisa dilakukan pencarian berdasarkan isi dokumen sehingga dapat mempermudah proses pengelolaan dokumen serta meningkatkan efisiensi waktu. Ancaman bagi Document Management adalah adanya cybercrime dari luar perusahaan maupun dalam perusahaan karena saat ini Document Management merupakan platform berbasis Web dan masih dimonitor oleh unit IT-Security untuk keamanannya, kemudian jika perangkat keras penyimpanannya hilang atau rusak, dan adanya teknologi yang saat ini terus berkembang pesat.

\subsubsection{Analisis Value Chain}

\begin{tabular}{|c|c|c|c|c|}
\hline \multicolumn{5}{|c|}{ Penggunaan Aplikasi Vportal } \\
\hline \multicolumn{5}{|c|}{ Pengaturan Sumber Daya Manusia } \\
\hline \multicolumn{5}{|c|}{ Pengembangan SI dan TI } \\
\hline \multicolumn{5}{|c|}{ Menerapkan QMS (Quality Management System) } \\
\hline $\begin{array}{l}\text { Pembuatan } \\
\text { Dokumen } \\
\text { (Policy, WI, } \\
\text { dan } \\
\text { Procedure) }\end{array}$ & $\begin{array}{l}\text { Pemeriksaan } \\
\text { dokumen, } \\
\text { revisi } \\
\text { dokumen, } \\
\text { penyetujuan } \\
\text { dokumen }\end{array}$ & $\begin{array}{c}\text { Penerbitan } \\
\text { dokumen }\end{array}$ & $\begin{array}{l}\text { Penyuluhan } \\
\text { ke karyawan }\end{array}$ & $\begin{array}{c}\text { Delivery } \\
\text { dokumen } \\
\text { dengan cepat, } \\
\text { teknisi yang } \\
\text { handal dalam } \\
\text { troubleshooti } \\
n g\end{array}$ \\
\hline
\end{tabular}

Gambar 1. Hasil Analisis Value Chain 
Menurut dengan Gambar 1, dapat dijabarkan hasil analisis Value Chain sebagai berikut :

1. Aktivitas Utama

a. Inbound Logistics

- Pembuatan dokumen seperti dokumen kebijakan (Policy), dokumen instruksi kerja (Work-Instruction), dan dokumen

b. Operations prosedur (Procedure).

- Pemeriksaan dokumen.

- Proses revisi dokumen.

c. Outbound Logistics

- Penyetujuan dokumen.

d. Sales \& Marketing

e. Servicing

- Penyuluhan ke karyawan.

- Delivery dokumen ke setiap bagian unit dapat diakses dengan cepat.

- Teknisi yang handal dalam troubleshooting jika Document

2. Aktivitas Pendukung Management mengalami kendala.

a. Support Activities Infrastructure

- Penggunaan aplikasi Vportal. Dimana fungsi dari aplikasi Vportal untuk melihat semua prosedur kerja yang ada di PT. Visionet Data International.

b. Human Resource Management

- Pengaturan Sumber Daya Manusia.

c. Product and Technology Development

- Pengembangan SI dan TI.

d. Procurement

- Menerapkan QMS (Quality Management System). Dimana tim QMS melakukan induction training mengenai konsep dasar QMS, garis besar mengenai ISO 9001, dan mengenai Compliance Management System.

\subsubsection{Analisis PEST}

Analisis PEST merupakan alat untuk menganalisis operasi lingkungan bisnis eksternal pada PT. Visionet Data International terkhususnya Document Management dilihat dari Politik, Ekonomi, Sosial, dan Teknologi. Berikut analisanya :

1. Politik

a. Adanya regulasi dari pemerintah yang menyangkut dengan ketenagakerjaan dimana akan berpengaruh terhadap kebijakan di PT. Visionet Data International itu sendiri yang mana juga terus 2. Ekonomi menyesuaikan dengan regulasi dari pemerintah yang terkini.

a. Mengikuti kontrak atau PKS (Perjanjian Kerja Sama) antara pelanggan dan perusahaan yang telah dibuat dan ditetapkan bersama dalam jangka waktu tertentu. Namun dapat diubah jika ada perubahan yang dianggap perlu. 
3. Sosial

a. Mengikuti pedoman tingkah laku atau yang lebih dikenal dengan COC (Code Of Conduct) yang menjelaskan antara lain mengenai pemberian hadiah, benturan kepentingan (Conflict of Interest), kerahasiaan informasi, pelaporan atas pelanggaran, potensi pelanggaran, pemalsuan, penipuan, korupsi, dan hal lain yang berkaitan dengan tindakan criminal dan kejadian sejenisnya.

4. Teknologi

a. Mengikuti perkembangan teknologi terbaru sehingga dapat menunjang keberhasilan bisnis serta dapat memenuhi tujuan perusahaan di PT. Visionet Data International.

b. Diadakan perawatan server atau maintenance yang secara berkala agar dapat meminimalisir kerusakan yang tidak diinginkan. Seperti update patch yang harus dilakukan. Saat dilakukan update patch tersebut aplikasi Document Management akan terganggu yang menyebabkan tidak bisa diakses selama update patch sedang berlangsung.

c. Pemantuan keamanan data server dari serangan cyber secara 24 jam.

\subsection{Analisis Lingkungan SI/TI Internal dan Eksternal \\ 3.3.1 Analisis Lingkungan SI/TI Internal}

Dalam penggunaan teknologi di PT. Visionet Data International terkhusunya bagi Document Management sendiri telah menggunakan aplikasi Vportal sebagai alat bantu untuk menyimpan seluruh prosedur kerja yang ada di PT. Visionet Data International. Dimana yang dapat diakses atau dilihat oleh member PT. Visionet Data International dimanapun dan kapanpun. PT. Visionet Data International juga menggunakan aplikasi I-Top dimana fungsinya adalah untuk melakukan tracking dokumen (pengajuan dan revisi) yang terintegrasi dengan aplikasi bernama Viona. Track yang dicatat pada aplikasi I-Top berupa tanggal pengajuan dokumen, judul dokumen, dan batas persetujuan dokumen. Untuk aplikasi internal termasuk Vportal penganggung jawab berada di Tim CADaS (Corporate Applications Development and Support). Sehingga saat sedang melakukan maintenance, Tim Internal Support di sisi perangkat jaringan dan perangkat keras (termasuk server) beserta Tim CADaS di sisi perangkat lunak akan bekerja sama untuk melakukan maintenance.

\subsubsection{Analisis Lingkungan SI/TI Eksternal}

Perkembangan teknologi memang sangat berpengaruh dalam menunjang keberhasilan bisnis disuatu organisasi maupun perusahaan terutama yang bergerak dibidang TI. Dalam perkembangan teknologi yang ada di PT. Visionet Data International sudah sejalan dengan perkembangan teknologi saat ini dalam bentuk langsung maupun tidak langsung sebab akan berdampak pada proses bisnis dari pada perusahaan. Seperti halnya dalam Document Management untuk meningkatkan peluang dalam mencapai suatu tujuan perusahaan maka PT. Visionet Data International perlu mengikuti regulasi yang ada dari luar perusahaan seperti dalam bentuk standarisasi yang berlaku. Maka Document Management saat ini sudah tersertifikasi 3 ISO yaitu : ISO 9001:2005, ISO 27001:2013, dan ISO 20000-1:2011. Sebab sekarang telah memasuki era Industri 4.0 dimana dalam era tersebut IOT (Internet of Things) atau dalam artian internet untuk segalanya akibat pesatnya perkembangan internet. Dengan demikian perusahaan atau organisasi terlebihnya perusahaan bergerak dibidang TI perlu mengikuti era tersebut juga. 


\subsection{Matrik SWOT}

Dari semua hasil analisis yang sudah dilakukan maka langkah selanjutnya adalah pemodelan hasil analisis menggunakan Matrik SWOT. Dimana hasil dari Matrik SWOT merupakan kesimpulan dari semua analisis yang ditarik lurus agar menjadikan strategi yang tepat. Berikut hasil Matrik SWOT yang digambarkan pada tabel 1.

\begin{tabular}{|c|c|}
\hline S-O & S-T \\
\hline $\begin{array}{l}\text { 1. Melakukan pengembangan lebih } \\
\text { lanjut beserta meningkatkan } \\
\text { penggunaan dokumentasi } \\
\text { berbasis online (WEB) agar dapat } \\
\text { diakses dimanapun dan kapanpun } \\
\text { oleh member perusahaan. } \\
\text { 2. Dapat diintegrasikan menjadi } \\
\text { satu kesatuan dalam bentuk } \\
\text { aplikasi, sehingga memberikan } \\
\text { efektifitas dan efisiensi waktu } \\
\text { dalam pengelolaan dokumentasi } \\
\text { perusahaan oleh member } \\
\text { perusahaan. }\end{array}$ & $\begin{array}{l}\text { 1. Meningkatkan keamanan sistem } \\
\text { informasi. } \\
\text { 2. Meningkatkan bentuk induction } \\
\text { training ke karyawan baru } \\
\text { maupun karyawan lama. }\end{array}$ \\
\hline W-O & W-T \\
\hline $\begin{array}{l}\text { 1. Membangun sistem mesin } \\
\text { pencarian (search engine) yang } \\
\text { dapat mencari berdasarkan isi } \\
\text { dokumen, judul dokumen, dan } \\
\text { jenis dokumen. }\end{array}$ & $\begin{array}{l}\text { 1. Meningkatkan frekuensi audit } \\
\text { didalam perusahaan. }\end{array}$ \\
\hline
\end{tabular}

Tabel 1. Matrik SWOT

\subsection{Usulan Sistem Informasi}

Kemudian dilakukan pembuatan Usulan Sistem Informasi berdasarkan hasil analisa di sistem agar menghasilkan rekomendasi apa saja bentuk strategi yang akan digunakan sehingga juga menghasilkan penyusunan portofolio aplikasi untuk beberapa tahun mendatang bagi Document Management di PT. Visionet Data International. Berikut hasil bentuk Usulan Sistem Informasi pada tabel 2.

\begin{tabular}{|c|c|c|c|c|}
\hline No. & $\begin{array}{c}\text { Nama Sistem } \\
\text { Informasi }\end{array}$ & Pengguna & $\begin{array}{c}\text { Jenis } \\
\text { Aplikasi }\end{array}$ & Fungsi \\
\hline 1. & $\begin{array}{l}\text { Aplikasi Document } \\
\text { Management }\end{array}$ & Customer & WEB & 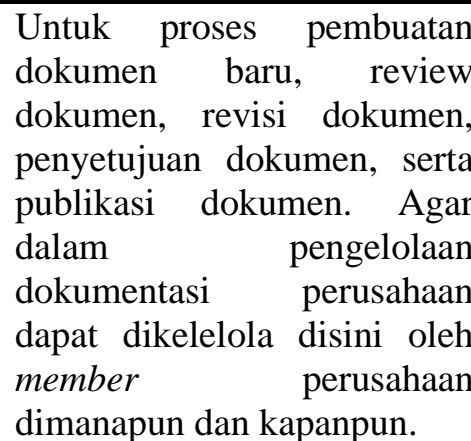 \\
\hline
\end{tabular}


2. Fitur pencarian dokumen Customer WEB berdasarkan isi dokumen

Untuk mempermudah dalam pencarian dokumentasi perusahaan. Dengan cara membangun search engine yang dirancang khusus untuk mencari berdasarkan isi konten pada dokumentasi. Sehingga dapat meningkatkan efisiensi waktu kerja.

3. Fitur remark pada Customer WEB dokumen yang ter-rejected

Untuk mengurangi penggunaan kertas sehingga dalam tahap revisi dokumen yang diajukan maupun dokumen yang diperbaharui dapat dilakukan melalui aplikasi tanpa melalui hardcopy.

4. Membangun sistem Karyawan WEB Knowledge Management Untuk media penyaluran ilmu ke semua karyawan di perusahaan.

System

5. Fitur penandatanganan Customer WEB Demi menunjang mengurangi dengan digital signature

pemakaian kertas dan
meningkatkan efisiensi
waktu, tanda tangan dapat
berupa berupa digital
signature pada dokumen yang
sudah disetujui.

Tabel 2. Usulan Sistem Informasi

\subsection{Portofolio Aplikasi}

Dari analisa yang telah dilakukan terhadap lingkungan bisnis maupun kondisi SI/TI dalam ruang lingkup internal dan eksternal pada perusahaan maka langkah selanjutnya adalah penyusunan portofolio aplikasi untuk beberapa tahun mendatang. Dimana penyusunan ini menggunakan metode yang dikeluarkan oleh Mc Farlan Grid. Dalam pemetakan aplikasi menggunakan metode Mc Farlan Grid terdapat empat kuadran yaitu Strategic, High Potential, Key Operation, dan Support. Berikut hasil penyusunan Portofolio Aplikasi disusun pada tabel 3.

\begin{tabular}{lll}
\hline STRATEGIC & & HIGH POTENTIAL \\
\hline - Fitur Mesin Pencarian (Search & $\bullet$ & Aplikasi Dokumen Management \\
$\begin{array}{l}\text { Engine) berdasarkan isi konten } \\
\text { dokumen }\end{array}$ & $\bullet$ Membuat sistem Knowledge \\
- Fitur Penandatanganan dengan System
\end{tabular}

- Fitur Penandatanganan dengan Digital Signature

- Fitur remark pada dokumen yang ter-rejected 
- Aplikasi Vportal

- Aplikasi I-Top

- Aplikasi Viona
- E-mail

- Aplikasi Slack

Tabel 3. Portofolio Aplikasi Mc Farlan

\subsection{Analisa Kesenjangan Aplikasi}

Analisis Kesenjangan Aplikasi (GAP Analysis) merupakan alat untuk menentukan mengetahui apakah sistem yang ada diperusahaan saat ini sudah memenuhi kebutuhan perusahaan atau belum serta mengidentifikasi bentuk kesenjangannya untuk kondisi masa depan yang diinginkan. Berikut hasil analisa kesenjangan aplikasi disusun pada tabel 4 .

\begin{tabular}{lccc}
\hline \multicolumn{1}{c}{ Usulan Sistem Informasi } & Upgrade & Delete & Planning \\
\hline Aplikasi Document Management & - & - & $\checkmark$ \\
Fitur Mesin Pencarian (Search Engine) & - & - & $\checkmark$ \\
Fitur Penandatangan (Digital Signature) & - & - & $\checkmark$ \\
Fitur remark pada dokumen yang ter-rejected & - & - & $\checkmark$ \\
Aplikasi Vportal & $\checkmark$ & - & - \\
Aplikasi I-Top & $\checkmark$ & - & - \\
Aplikasi Viona & $\checkmark$ & - & - \\
E-mail & $\checkmark$ & - & - \\
Aplikasi Slack & $\checkmark$ & - & - \\
Membuat sistem Knowledge Management System & - & - & $\checkmark$
\end{tabular}

Tabel 4. Analisa Kesenjangan Aplikasi

\section{KESIMPULAN DAN SARAN}

\subsection{Kesimpulan}

Berdasarkan hasil penelitian dan data yang didapat di PT. Visionet Data International dan dianalisis dengan menggunakan metode Ward And Peppard menghasilkan bentuk rekomendasi portofolio aplikasi seperti pengembangan Document Management dalam bentuk aplikasi berbasis Web yang semua proses didalamnya terintegrasi menjadi satu. Sehingga dapat mendorong efisiensi dan efektivitas waktu diruang lingkup PT. Visionet Data Internasional. Beserta analisa kesenjangan yang dimana kedepannya dapat direalisasikan hingga dikembangkan serta dapat menjadi kontribusi untuk kesuksesan bisnis pada PT. Visionet Data International.

\subsection{Saran}

Saran untuk penelitian selanjutnya adalah diharapkan dapat meneliti dalam ruang lingkup dan menggunakan metode penelitian yang lebih luas. Karena dalam penelitian Perencanaan Strategis Sistem Informasi / Teknologi Informasi Pada Document Management Menggunakan Ward And Peppard (Studi Kasus : PT. Visionet Data International) hanya berfokus dalam aplikasi SI/TI yang menyangkut soal pengelolaan dokumentasi perusahaan. Diharapkan kedepannya semua hasil usulan dari penelitian ini dapat diimplementasikan dan dikembangkan pada penelitian selanjutnya. 


\section{Referensi}

[1] I. G. Susanto and A. F. Wijaya, "RENSTRA SI ATAU TI UNIT BISNIS (BRANCH IT SERVICES) MENGGUNAKAN METODE WARD AND PEPPARD ( STUDI KASUS: PT. XYZ )," J. UMK, vol. Vol 1, No, pp. 1-6, 2018.

[2] A. Wedhasmara, "Langkah-Langkah Perencanaan Strategis Sistem Informasi Dengan Menggunakan Metode Ward and Peppard," J. Sist. Inf., vol. 1, no. 1, pp. 14-22, 2009.

[3] Y. Septiana, "PERENCANAAN STRATEGIS SISTEM INFORMASI DENGAN PENDEKATAN WARD AND PEPPARD MODEL ( Studi Kasus : Klinik INTI Garut ) PERENCANAAN STRATEGIS SISTEM INFORMASI DENGAN PENDEKATAN WARD AND PEPPARD MODEL ( Studi Kasus : Klinik INTI Garut )," Wawasan Ilm., vol. 8, no. May, pp. 8-24, 2017.

[4] J. Fahana, "Perencanaan Strategis Sistem Informasi untuk Pengelolaan Guru Sekolah Muhammadiyah," J. Ilm. Tek. Elektro Komput. dan Inform., vol. 4, no. 1, p. 51, 2018.

[5] K. Tri Setiadi and A. R. Tanaamah, "Perencanaan Strategis Sistem Informasi Menggunakan Metode Ward and Peppard Pada YLPHS," SEMNAS RISTEK 2019, 2019.

[6] K. Imtihan, "Perencanaan Strategi Sistem Informasi Pendidikan Pada Sekolah Tinggi Manajemen Informatika dan Komputer ( STMIK ) Lombok," Bianglala Inform., vol. 3, no. 2, pp. 73-78, 2015.

[7] Y. Firmansyah and D. Purwaningtias, "Analisa Metodologi Ward \& Peppard Dalam Penentuan Perencanaan Strategis SI/TI," Cybernetics, vol. 1, no. 02, p. 70, 2017.

[8] P. V. D. International, "Visi dan Misi PT. Visionet Data International." [Online]. Available: https://www.visionet.co.id/id/overview-id/visi-dan-misi/. [Accessed: 20-Jan2020]. 